\title{
The SPARK Study: a phase II randomized blinded controlled trial of the effect of furosemide in critically ill patients with early acute kidney injury
}

\author{
Sean M Bagshaw ${ }^{1 *}$, RT Noel Gibney ${ }^{1}$, Finlay A McAlister ${ }^{2}$, Rinaldo Bellomo ${ }^{3}$
}

\begin{abstract}
Background: Furosemide is commonly prescribed in critically ill patients with acute kidney injury (AKI). Existing data from observational studies and small clinical trials have significant limitations and have reported conflicting findings. There remains controversy on whether furosemide can impact clinical outcomes in critically ill patients with AKl; however, a survey of intensivists and nephrologists showed equipoise for high-quality evidence on this important issue.

Design/Methods: This protocol summarizes the rationale and design of a phase II randomized, blinded, placebocontrolled trial of a low-dose continuous infusion of furosemide, titrated to the physiology parameter of urine output, in critically ill patients with early AKI. Two hundred sixteen adult critically ill patients with early evidence of AKI, defined by the RIFLE criteria, will be enrolled. Included patients will also have fulfilled $\geq 2$ criteria of the systemic inflammatory response syndrome and achieved immediate goals of acute resuscitation. The primary outcome is progression in severity of kidney injury. Secondary outcomes include: safety, fluid balance, electrolyte balance, the need for renal replacement therapy, duration of AKI, rate of renal recovery, mortality and changes in novel serum and urine biomarkers of AKI. The primary analysis will be intention-to-treat. Planned recruitment will be complete by June 2011 and results available by December 2011.
\end{abstract}

Trial Registration: ClinicalTrials.gov Identifier NCT00978354

\section{Background}

Acute kidney injury (AKI) is common and increasingly encountered in hospitalized patients [1-3]. An estimated $6 \%$ of critically ill patients admitted to intensive care (ICU) develop severe AKI, and approximately 70\% eventually receive acute renal replacement therapy (RRT)[4]. Moreover, critical illness complicated by AKI remains associated with high morbidity, mortality and health resource use [4-11].

There are few, if any, interventions proven to impact on the clinical course and outcome for critically ill patients once AKI is established[12,13]. However, important questions remain regarding the supportive role of selected interventions that still demand higherquality evidence and better characterization in

\footnotetext{
* Correspondence: bagshaw@ualberta.ca

'Division of Critical Care Medicine, Faculty of Medicine and Dentistry, University of Alberta, 3C1.12 Walter C. Mackenzie Centre, 8440-112 Street, Edmonton, Alberta T6G 2B7, Canada
}

(c) 2010 Bagshaw et al; licensee BioMed Central Ltd. This is an Open Access article distributed under the terms of the Creative Commons Attribution License (http://creativecommons.org/licenses/by/2.0), which permits unrestricted use, distribution, and reproduction in any medium, provided the original work is properly cited. randomized trials to evaluate their impact in AKI. One example is: what is the role for loop diuretics, specifically furosemide, in the management of critically ill patients with early AKI?

Furosemide acts at the medullary thick ascending loop of Henle to inhibit the $\mathrm{Na}+/ \mathrm{K}+/ \mathrm{Cl}-$ pump on the luminal cell membrane surface and can theoretically reduce renal tubular oxygen demand[14,15]. Experimental data have also suggested low-dose furosemide infusion may attenuate ischemia/reperfusion-induced apoptosis and associated gene transcription in AKI $[16,17]$. These data support the hypothesis that the timely administration of furosemide may attenuate and/or reduce the severity of early onset AKI. In addition, furosemide may also have an important adjuvant role for maintaining fluid homeostasis and for optimal delivery of nutrition in critically ill AKI patients[18,19].

Furosemide remains the most common loop diuretic prescribed in critically ill patients[20]. In the BEST 
Kidney Study, a large multi-centre observational study of $>1700$ critically ill patients with AKI, 70\% had received diuretics at the time of enrollment, of whom $98 \%$ were receiving furosemide[21]. While numerous studies have evaluated loop diuretics in the treatment of AKI [22-30], the majority have failed to find consistent clinical benefit. Moreover, two large observational studies of AKI in critically ill patients have reported discrepant findings on the effect of loop diuretics on mortality and renal recovery[21,31]. Additional small trials have suggested that diuretics may reduce the severity of kidney injury by converting "oliguric" to "non-oliguric" AKI, shorten the duration of AKI, improve the rate of renal recovery, and perhaps delay or ameliorate need for RRT [22,24,32-35]. However, improvements in survival or renal recovery have yet to be confirmed with high-quality evidence. Accordingly, there is controversy as to whether furosemide can impact clinical outcomes and should be used in critically ill patients with AKI [36-40].

A recent systematic review of randomized trials assessing the role of loop diuretics in AKI found five trials enrolling 555 patients that focused on critically ill patients[41]. This review found no statistical difference in mortality (odds ratio [OR], $1.28, \mathrm{p}=0.18$ ) or renal recovery $(\mathrm{OR}, 0.88, \mathrm{p}=0.5)$ for use of loop diuretics compared with control. However, loop diuretics were associated with a shorter duration of RRT (weighted mean difference, -1.4 days, $\mathrm{p}=0.02$ ), shorter time to spontaneous decline in serum creatinine (weighted mean difference, -2.1 days, $\mathrm{p}=0.01$ ) and a greater increase in urine output from baseline (OR, 2.6, $\mathrm{p}=0.004)$. There was insufficient data to comment on the impact of loop diuretics on electrolyte abnormalities, fluid balance, duration of mechanical ventilation, secondary organ dysfunction, hospital length of stay or health costs.

Importantly, however, this review found that the overall trial quality and applicability of this evidence to critically ill patients was poor[41]. For example, trials were generally small, confounded by co-interventions (i.e. mannitol, dopamine), and characterized by delayed or late intervention (i.e. prolonged periods of oligo-anuria or already receiving RRT at the time of enrollment). Finally, these trials often administered furosemide as large intravenous bolus doses with no specific titration of therapy to physiologic endpoints such as urine output. As a consequence, these data have limited applicability to modern critically ill patients and to current ICU practice.

A recent multi-national survey of intensivists and nephrologists showed that most respondents did not believe that furosemide use in AKI would directly improve outcomes such as mortality, need for RRT, or renal recovery[20]. However, there was significant uncertainty about the existing evidence and the majority had equipoise for and supported a trial on this issue. Accordingly, we have proposed a phase II randomized, blinded, placebo-controlled trial of a furosemide infusion titrated to urine output in critically ill patients with early AKI.

\section{Objectives}

The specific objectives of this trial are:

- To compare the efficacy and safety of a continuous infusion of furosemide versus placebo titrated to the physiology parameter of urine output in early AKI on the primary outcome of progression in severity of kidney injury from early AKI.

- To evaluate the impact of furosemide versus placebo on key secondary endpoints including: fluid balance; electrolyte and acid-base balance; the need for RRT; total duration of AKI; the rate of renal recovery; and mortality.

- To evaluate the impact of furosemide versus placebo on the tertiary endpoint of differences, trajectory and prognostic value of novel serum and urine biomarkers for AKI.

\section{Design/Methods}

\section{Study Design, Setting and Patient Population}

This is a phase II randomized, blinded, placebo-controlled trial of ICU patients with early AKI with randomization stratified by sepsis. This study will be performed at the University of Alberta Hospital (UAH) General Systems Intensive Care Unit (GSICU). The $\mathrm{UAH}$ is an academic/tertiary care hospital and regional trauma centre with approximately 1300-1400 annual admissions. All patients admitted to the GSICU will be screened for eligibility.

\section{Operational Definitions}

\section{Acute kidney injury (AKI)}

The operational definition for early AKI will be defined and classified according to a modified RIFLE criteria (acronym indicating Risk of renal dysfunction; Injury to the kidney; Failure of kidney function; Loss of kidney function; and End-stage kidney disease) as outlined by the ADQI Working Group [42]. In brief, the RIFLE criteria classifies AKI into three categories of severity (Risk, Injury, and Failure) and two categories of clinical outcome (Loss and End-stage kidney disease) based on relative changes to serum creatinine and urine output. The presence of early AKI will be defined by a minimum of RIFLE class - RISK: an abrupt (within 7 day) reduction in kidney function characterized by an relative increase in serum creatinine of $\geq 50 \%$ ( 1.5 fold) or an absolute increase of $\geq 26.5 \mu \mathrm{mol} / \mathrm{L}$ from baseline or a 
reduction in urine output of $\leq 0.5 \mathrm{~mL} / \mathrm{kg} / \mathrm{hr}$ for $\geq 6$ hours. For reference, the RIFLE category INJURY is defined as a relative increase in serum creatinine $\geq 100 \%$ ( 2.0 fold) or a reduction in urine output of $\leq 0.5$ $\mathrm{mL} / \mathrm{kg} / \mathrm{hr}$ for $\geq 12$ hours. The RIFLE category FAILURE is defined as a relative increase in serum creatinine $\geq 200 \%$ (3.0 fold) or an absolute value $\geq 354 \mu \mathrm{mol} / \mathrm{L}$ (accompanied by an acute increase $\geq 44.2 \mu \mathrm{mol} / \mathrm{L}$ ) or a reduction in urine output of $\leq 0.3 \mathrm{~mL} / \mathrm{kg} / \mathrm{hr}$ for $\geq 24$ hours or anuria for $\geq 12$ hours.

\section{Renal replacement therapy (RRT)}

The operational definition of RRT will incorporate any form of extracorporeal renal support or replacement for patients with documented AKI. By protocol and in order to minimize the potential bias of clinician discretion on when to initiate RRT, at least one of the following criteria must be fulfilled prior to initiation of RRT: 1) refractory oliguria (urine output $<100 \mathrm{~mL}$ in preceding $4 \mathrm{hrs}$, despite fluid resuscitation and/or vasoactive therapy F OR maximum dose of study drug); 2) refractory extravascular fluid overload AND/OR hypoxemia AND/OR pulmonary edema ( $\mathrm{FiO} 2 \geq 60 \%$, receiving mechanical ventilation, $\mathrm{PaO} 2 / \mathrm{FiO} 2$ ratio $\leq 200$ ); 3 ) azotemia (urea $\geq 30 \mathrm{mmol} / \mathrm{L}$ ); 4) metabolic acidosis $(\mathrm{pH}<7.2$ or HCO3 $<15)$; hyperkalemia $\left(\left[\mathrm{K}^{+}\right] \geq 6.0 \mathrm{mmol} / \mathrm{L}\right.$ or electrocardiogram changes, despite maximum dose of study drug AND/OR administration of at least 1 dose of potassium binder AND/OR intravenous insulin AND/ OR intravenous bicarbonate; 5) uremia-induced organ toxicity (i.e. encephalopathy, pericarditis).

\section{Renal recovery}

The operational definition of renal recovery will be the return of serum creatinine to within $10 \%$ of baseline levels and a spontaneous urine output $\geq 1.0 \mathrm{~mL} / \mathrm{kg} / \mathrm{hr}$ for a minimum of 24 hours independent of RRT.

\section{Systemic inflammatory response syndrome (SIRS)}

The SIRS criteria include the presence of any 2 of the following: temperature $>38^{\circ} \mathrm{C}$ or $<36^{\circ} \mathrm{C}$; heart rate $>90$ beats/min; respiratory rate $>20$ breaths $/$ min or $\mathrm{PaCO}_{2}$ $<32 \mathrm{mmHg}$ or mechanically ventilated; and/or white cell count $>12,000$ cells $/ \mathrm{mm}^{3},<4,000$ cells $/ \mathrm{mm}^{3}$ or with $>10 \%$ immature (band) forms[43].

\section{Sepsis}

The operational definition of the clinical syndrome of sepsis will be the presence of confirmed or suspected infection and the presence of $\geq 2$ SIRS criteria.

\section{Inclusion Criteria}

Patients must fulfill all of the following inclusion criteria:

\footnotetext{
- Peripheral or central intravenous catheter and urinary catheter

- Early AKI
}

- $\geq 2$ criteria for the systemic inflammatory response syndrome (SIRS) within 24 hours

- Achieved immediate resuscitation goals (as directed by the treating physician) including fluid resuscitation AND/OR vasoactive therapy to achieve mean arterial pressure $\geq 65 \mathrm{mmHg}$, central venous pressure $\geq 8 \mathrm{cmH} 2 \mathrm{O}$, central venous oxygen saturation $\geq 70 \%$ (if measured) AND/OR cardiac index $\geq 2.5 \mathrm{~L} / \mathrm{min} /$ $1.73 \mathrm{~m}^{2}$ (if measured).

\section{Exclusion criteria}

The following conditions will lead to ineligibility for study entry:

- Age $<18$ years

- Confirmed or suspected pregnancy (verified by serum $[\beta-\mathrm{HCG}]$ pregnancy test if necessary)

- Obstructive etiology for AKI

- $\geq$ Stage 4 chronic kidney disease (defined by an estimated glomerular filtration rate $<30 \mathrm{~mL} / \mathrm{min} /$ $1.73 \mathrm{~m}^{2}$ ), end stage kidney disease on chronic RRT, kidney transplantation or already received RRT in ICU

- Resolving AKI, defined as a $\geq 25 \%$ or $\geq 44.2 \mu \mathrm{mol} / \mathrm{L}$ decline from peak increase in serum creatinine - Acute pulmonary edema requiring urgent use of furosemide or RRT or patient already receiving continuous furosemide infusion

- Patient is moribund with expected death within 24 hours

- Known or suspected drug allergy to furosemide

- Enrolled in concomitant randomized trial

- Prior enrollment in SPARK

\section{Trial Protocol}

\section{Description of Study Flow}

Figure 1 outlines the study flow. Patients will be identified in the ICU by daily surveillance by the research coordinator or when identified by the treating ICU physician. Each patient's eligibility will be verified by use of a one-page checklist that summarizes the inclusion and exclusion criteria. This checklist will be included in the standardized case-report form (CRF).

\section{Study Intervention}

Patients will be commenced on a continuous infusion of either the intervention (furosemide) or identical placebo $(0.9 \% \mathrm{NaCl})$. The study protocol for administration of furosemide by continuous infusion is adapted from the phase I study by Ostermann et al [44] (Figure 2).

The study infusion bag will contain $2000 \mathrm{mg}$ of furosemide in $500 \mathrm{~mL}$ of $0.9 \% \mathrm{NaCl}$ for a final concentration 


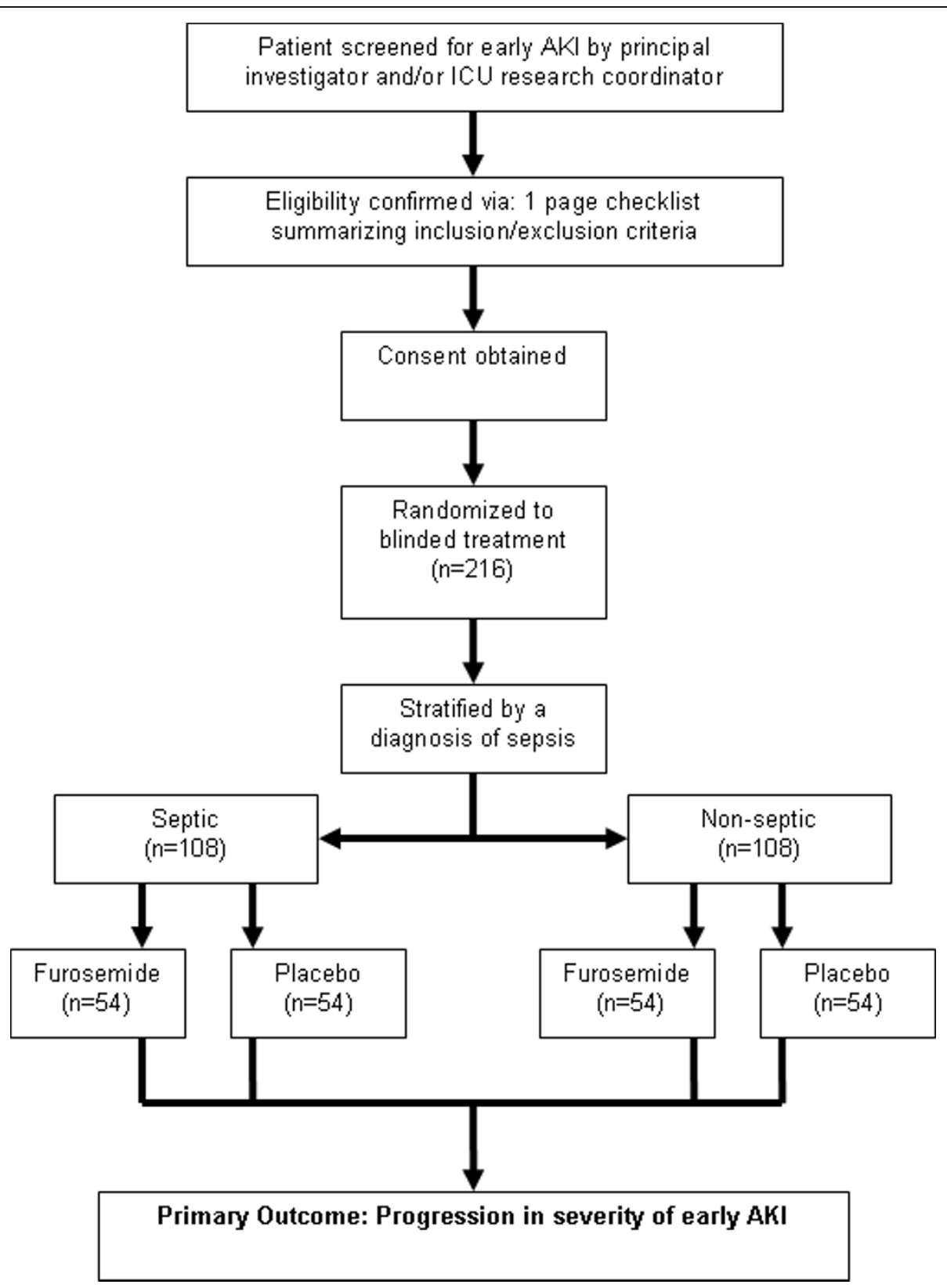

Figure 1 Overview of patient flow.

of $4 \mathrm{mg} / \mathrm{mL}$. The appearance of the study infusion bags for furosemide and placebo will be identical and there will be no marking on the infusion bags other than a 4digit coded identifying study number. This will minimize bias and ensure blinding of allocation by the study investigators, research coordinator, ICU physicians and all involved health care providers.

The continuous infusion will be titrated to achieve a target urine output in the range of $1.0-2.0 \mathrm{~mL} / \mathrm{kg} / \mathrm{hr}$. The treatment algorithm for titration of the continuous infusion is shown in Figure 2. Each patient will be administered a loading dose of $0.4 \mathrm{mg} / \mathrm{kg}$ as a separate infusion bag followed by a continuous infusion commenced at a dose of $0.05 \mathrm{mg} / \mathrm{kg} / \mathrm{hr}$ (Table 1). The maximum infusion rate will be $0.40 \mathrm{mg} / \mathrm{kg} / \mathrm{hr}$. The urine output will be assessed hourly. If the target urine output has been achieved, then the current infusion rate will be continued. If the target urine output has not been achieved, the dose will be increased to the next infusion rate in the algorithm. If the urine output is too brisk ( $>2 \mathrm{~mL} / \mathrm{kg} / \mathrm{hr} \times 2 \mathrm{hrs}$ ), the infusion rate will be reduced. If the urine output is still $>2 \mathrm{~mL} / \mathrm{kg} / \mathrm{hr}$ AND the 


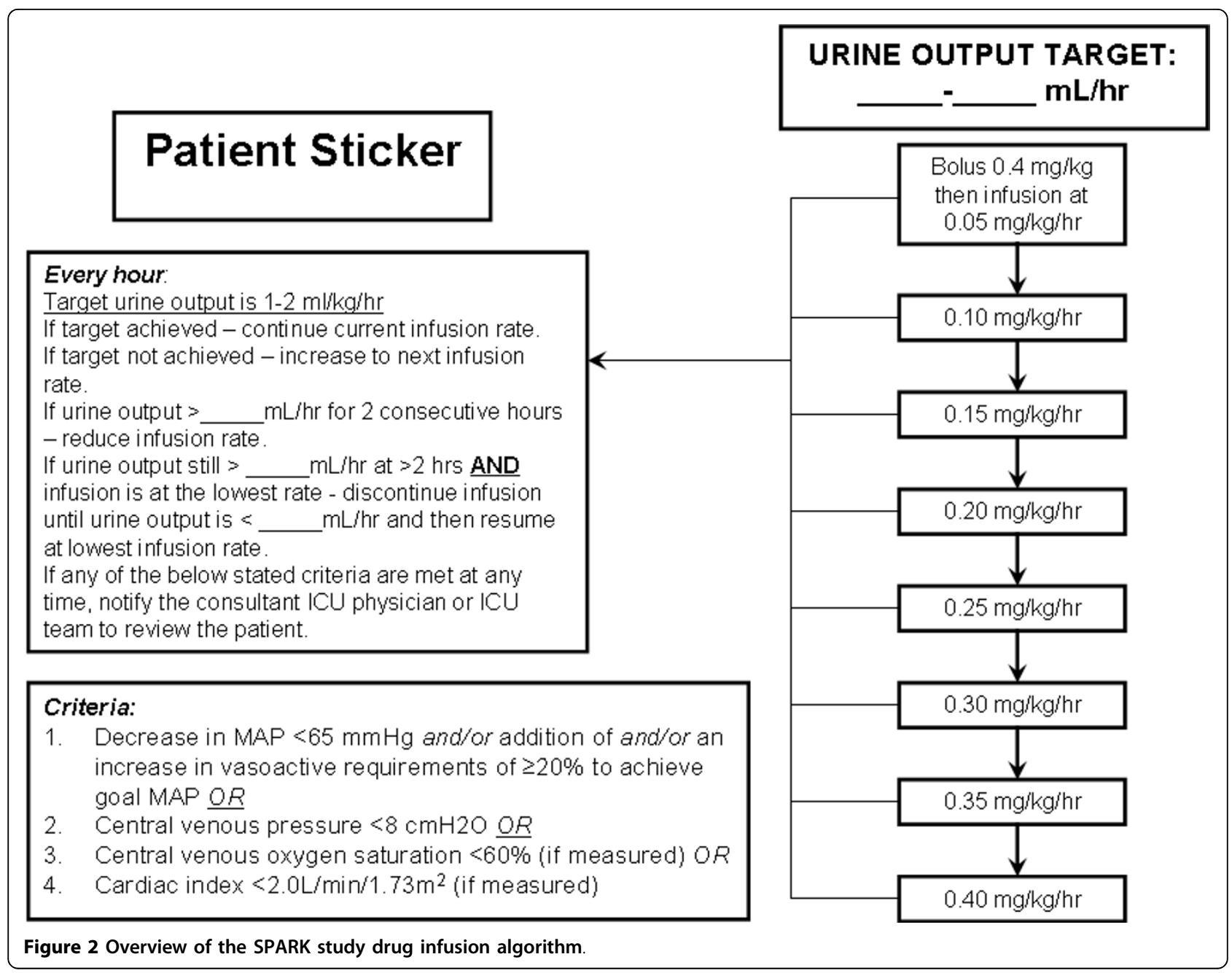

Table 1 Summary of weight-based categories for commencement for study infusion rate (concentration study drug $4 \mathrm{mg} / \mathrm{mL}$ )

\begin{tabular}{|c|c|c|c|c|}
\hline $\begin{array}{c}\text { Weight Category } \\
(\mathrm{kg})\end{array}$ & Bolus loading dose & Start infusion dose & $\begin{array}{c}\text { Start infusion dose } \\
(\mathrm{mg} / \mathrm{hr})\end{array}$ & $\begin{array}{c}\text { Start infusion rate } \\
(\mathrm{mL} / \mathrm{hr})\end{array}$ \\
\hline$\leq 50$ & $0.4 \mathrm{mg} / \mathrm{kg}$ & $0.05 \mathrm{mg} / \mathrm{kg} / \mathrm{hr}$ & 2.5 & 0.6 \\
\hline 55 & $0.4 \mathrm{mg} / \mathrm{kg}$ & $0.05 \mathrm{mg} / \mathrm{kg} / \mathrm{hr}$ & 2.8 & 0.7 \\
\hline 60 & $0.4 \mathrm{mg} / \mathrm{kg}$ & $0.05 \mathrm{mg} / \mathrm{kg} / \mathrm{hr}$ & 3.0 & 0.8 \\
\hline 65 & $0.4 \mathrm{mg} / \mathrm{kg}$ & $0.05 \mathrm{mg} / \mathrm{kg} / \mathrm{hr}$ & 3.3 & 0.8 \\
\hline 70 & $0.4 \mathrm{mg} / \mathrm{kg}$ & $0.05 \mathrm{mg} / \mathrm{kg} / \mathrm{hr}$ & 3.5 & 0.9 \\
\hline 75 & $0.4 \mathrm{mg} / \mathrm{kg}$ & $0.05 \mathrm{mg} / \mathrm{kg} / \mathrm{hr}$ & 3.8 & 0.9 \\
\hline 80 & $0.4 \mathrm{mg} / \mathrm{kg}$ & $0.05 \mathrm{mg} / \mathrm{kg} / \mathrm{hr}$ & 4.0 & 1.0 \\
\hline 85 & $0.4 \mathrm{mg} / \mathrm{kg}$ & $0.05 \mathrm{mg} / \mathrm{kg} / \mathrm{hr}$ & 4.3 & 1.1 \\
\hline 90 & $0.4 \mathrm{mg} / \mathrm{kg}$ & $0.05 \mathrm{mg} / \mathrm{kg} / \mathrm{hr}$ & 4.5 & 1.1 \\
\hline$\geq 95$ & $0.4 \mathrm{mg} / \mathrm{kg}$ & $0.05 \mathrm{mg} / \mathrm{kg} / \mathrm{hr}$ & 4.8 & 1.2 \\
\hline
\end{tabular}


infusion rate is at the lowest rate, the study drug will be discontinued infusion until the urine output is $<1 \mathrm{~mL} /$ $\mathrm{kg} / \mathrm{hr}$. If any of the following criteria are fulfilled: decrease in mean arterial pressure $<65 \mathrm{AND} / \mathrm{OR}$ addition of or an increase in vasoactive requirements of $\geq 20 \%$ to achieve goal mean arterial pressure OR central venous pressure $<8 \mathrm{cmH} 2 \mathrm{O}$ OR central venous oxygen saturation $<60 \%$ OR a cardiac index $<2.0 \mathrm{~L} / \mathrm{min} / 1.73 \mathrm{~m}^{2}$ (if measured) at any time, the consultant ICU physician and ICU team will be notified to review the patient.

An estimate of patient ideal body weight (IBW) will be used to determine the urine output target. Determination of estimated IBW will be based on the formula described by Devine[45] (Table 2). From this estimated IBW, patients will be divided into $5 \mathrm{~kg}$ weight categories to determine urine output goals for protocol simplicity (Table 3). At any time during the trial, if the responsible ICU physician believes that the administration of furosemide is urgently indicated (i.e. new pulmonary edema), it can be administered and this event will be documented.

Table 2 Devine formulate for ideal body weight estimation[45].

\begin{tabular}{|c|c|c|c|c|c|}
\hline Sex & \multicolumn{5}{|c|}{ Devine Formula } \\
\hline Female & \multicolumn{5}{|c|}{$\operatorname{IBW}(\mathrm{kg})=[45+(0.91 \times($ height in $\mathrm{cm}-152))]$} \\
\hline Male & \multicolumn{5}{|c|}{ IBW $(\mathrm{kg})=[50+(0.91 \times($ height in $\mathrm{cm}-152))]$} \\
\hline \multirow{2}{*}{$\begin{array}{c}\text { Height } \\
\text { (cm) }\end{array}$} & \multirow{2}{*}{$\begin{array}{c}\text { Height } \\
\text { (feet) }\end{array}$} & \multicolumn{2}{|c|}{ Female } & \multicolumn{2}{|c|}{ Male } \\
\hline & & $\begin{array}{l}\text { IBW } \\
(\mathrm{kg})\end{array}$ & Category & $\begin{array}{l}\text { IBW } \\
\text { (kg) }\end{array}$ & Category \\
\hline$\leq 152$ & $\leq 5^{\prime} 0$ & 45 & $\leq 50$ & 50 & $\leq 50$ \\
\hline 155 & $5^{\prime} 1$ & 47.7 & $\leq 50$ & 52.7 & 55 \\
\hline 157 & $5^{\prime} 2$ & 49.6 & $\leq 50$ & 54.6 & 55 \\
\hline 160 & $5^{\prime} 3$ & 52.3 & 55 & 57.3 & 60 \\
\hline 163 & $5^{\prime} 4$ & 55.0 & 55 & 60.0 & 60 \\
\hline 165 & $5^{\prime} 5$ & 56.8 & 60 & 61.8 & 65 \\
\hline 168 & $5^{\prime} 6$ & 59.6 & 60 & 64.6 & 65 \\
\hline 170 & $5^{\prime} 7$ & 61.4 & 65 & 66.4 & 70 \\
\hline 173 & $5^{\prime} 8$ & 64.1 & 65 & 69.1 & 70 \\
\hline 175 & $5^{\prime} 9$ & 65.9 & 70 & 70.9 & 75 \\
\hline 178 & $5^{\prime} 10$ & 68.7 & 70 & 73.7 & 75 \\
\hline 180 & $5^{\prime} 11$ & 70.5 & 75 & 75.5 & 80 \\
\hline 183 & $6^{\prime} 0$ & 73.2 & 75 & 78.2 & 80 \\
\hline 185 & $6{ }^{\prime} 1$ & 75.0 & 75 & 80.0 & 80 \\
\hline 188 & $6^{\prime} 2$ & 77.8 & 80 & 82.8 & 85 \\
\hline 191 & $6^{\prime} 3$ & 80.5 & 85 & 85.5 & 90 \\
\hline 193 & $6^{\prime} 4$ & 82.3 & 85 & 87.3 & 90 \\
\hline 196 & $6^{\prime} 5$ & 85.0 & 85 & 90.0 & 90 \\
\hline$\geq 198$ & $\geq 6^{\prime} 6$ & 86.9 & 90 & 91.9 & 95 \\
\hline
\end{tabular}

Table 3 Summary of weight-based urine output targets.

\begin{tabular}{ccccc}
\hline $\begin{array}{c}\text { Weight } \\
\text { Category } \\
\mathbf{( k g )}\end{array}$ & \multicolumn{5}{c}{ Target Urine Output (mL) } \\
\cline { 2 - 5 } & Hourly & $\begin{array}{c}\text { Per 6 } \\
\text { hours }\end{array}$ & $\begin{array}{c}\text { Per 12 } \\
\text { hours }\end{array}$ & $\begin{array}{c}\text { Per 24 } \\
\text { hours }\end{array}$ \\
\hline$\leq 50$ & $50-100$ & $300-600$ & $600-1200$ & $\geq 1200$ \\
\hline 55 & $55-110$ & $330-660$ & $660-1320$ & $\geq 1320$ \\
\hline 60 & $60-120$ & $360-720$ & $720-1440$ & $\geq 1440$ \\
\hline 65 & $65-130$ & $390-780$ & $780-1560$ & $\geq 1560$ \\
\hline 70 & $70-140$ & $420-840$ & $840-1680$ & $\geq 1680$ \\
\hline 75 & $75-150$ & $450-900$ & $900-1800$ & $\geq 1800$ \\
\hline 80 & $80-160$ & $480-960$ & $960-1920$ & $\geq 1920$ \\
\hline 85 & $85-170$ & $510-1020$ & $1020-2040$ & $\geq 2040$ \\
\hline 90 & $90-180$ & $540-1080$ & $1080-2160$ & $\geq 2160$ \\
\hline$\geq 95$ & $95-190$ & $570-1140$ & $1140-2280$ & $\geq 2280$ \\
\hline & & & & \\
\hline
\end{tabular}

All other aspects of patient management within the parameters outlined (i.e. methods of fluid resuscitation, choice of fluids, vasoactive therapy, choice of vasoactive therapy, adjuvant therapies such as hrAPC, intensive insulin therapy) will be at the discretion of the consultant ICU physician. No other interventions will be performed.

The study drug infusion will be continued for a minimum of $24 \mathrm{hrs}$ and discontinued if any one of the following events occurs:

- The patient is initiated on RRT;

- The patient is discharged from the ICU;

- The patient recovers kidney function;

- The patient dies;

- The patient develops a recognized adverse reaction potentially related to the study infusion; or

- The patient has received a total of 7-days of study drug administration.

\section{Methods of Randomization, Concealment and Blinding}

The randomization sequence will be created at a single central location at the Epidemiology and Research Coordinating Centre (EPICORE) at the University of Alberta (available at: http://www.epicore.ualberta.ca/index.html). This randomization sequence will be stratified by the presence of a diagnosis of sepsis. The clinical trial pharmacist (unblinded) will use a web-based randomization program to determine allocation of patients and then prepare the coded study solution. Each coded study solution bag will then be dispensed for administration to the patient as per protocol. This coded identifying study number will also be labeled on the patient CRF. The investigators, study coordinators, treating physicians, bedside nurses and patients/family will remain blinded to the allocated study solution. 


\section{Data Collection}

Detailed clinical, procedure-related, physiologic and laboratory data will be collected. Blood and urine will be collected at baseline, 12 hours, 24 hours and daily thereafter until participants exits the study. Data will be collected on standardized CRFs developed by the EPICORE centre. Completed CRF will be returned to the EPICORE centre, entered into a central database, where data queries will be generated.

Clinical data captured will include demographics, comorbidities and prescribed/current drug therapy. Details of admission diagnoses, surgical status, and dates of hospital and ICU admission will be recorded. Detailed data will be recorded on date of enrollment (i.e. fulfilling criteria for early AKI). This will include details of interventions (i.e. mechanical ventilation, vasoactive drugs, fluid therapy), hemodynamics (i.e. blood pressure, heart rate, central venous pressure), and acute physiology (i.e. components of severity of illness scores, urine output, fluid balance, secondary non-kidney organ dysfunction). During the trial, data will be collected daily on urine output, fluid balance, electrolytes, acid-base status, serum creatinine and urea. Collected blood and urine samples will be stored for batched analysis of kidney-injury specific biomarkers, including: serum and urine cystatin $\mathrm{C}$, serum and urine neutrophil gelatinase-associated lipocalin (NGAL), urine interleukin-18 (IL-18); urine kidney injury molecule-1 (KIM-1), and urine L-type fatty acid binding protein (L-FABP).

Data will be collected each day on whether the primary endpoint (progression of AKI) has occurred, for evidence of any secondary endpoints and for criteria for trial discontinuation.

Finally, any study protocol violations will be recorded. The adjudication of protocol violations will be determined by a study investigator blinded to the treatment allocation.

All enrolled patients will be followed to determine the duration of AKI, continued need for RRT, renal recovery and mortality until death or discharge from hospital and at 30, 60 and 90-days after randomization.

\section{Sample Size Estimation}

Our primary outcome measure for this trial is progression from early AKI (RIFLE class - RISK) to a more severe form of AKI, defined by progression in AKI to the development of either RIFLE class - Injury or Failure. Based on data from a large observational study, an estimated $60 \%$ of critically ill patients with early AKI worsen and develop further kidney injury[46]. We estimate that furosemide will contribute to a $20 \%$ absolute reduction in the proportion of those patients who progress from early AKI (RIFLE class - RISK) to either RIFLE class - Injury or Failure. This would require a total sample size of 214 patients and provide $80 \%$ power (alpha 0.05 ) for detection of a $20 \%$ difference in the proportion with progression of AKI. An estimated $50 \%$ of patients developing early AKI will have sepsis[47]. Randomization will be stratified by the presence of sepsis. The total sample size was increased to 216 patients to ensure a balanced number of patients in each treatment arm (Figure 1).

\section{Statistical Analysis}

The primary analysis will evaluate the proportion of critically ill patients with early AKI that have progression in kidney injury by having received furosemide or placebo. Analysis will be intention-to-treat.

The secondary analysis will evaluate for differences between furosemide and placebo in cumulative fluid balance and in the largest changes to serum potassium, serum magnesium, serum $\mathrm{pH}$ and serum bicarbonate levels, defined as difference from enrollment to lowest documented level during study infusion. In addition, this secondary analysis will evaluate for differences in the need for RRT, duration of AKI, rate of renal recovery and hospital mortality.

Descriptive statistics, boxplots and histograms will be used to analyze individual baseline variables by having received furosemide or placebo. Normally or near normally distributed, non-correlated variables will be reported as means with standard deviations (SD) and compared using the appropriate Student's t test. Nonnormally distributed, non-correlated continuous data will be reported as medians with inter-quartile ranges (IQR) and compared using the Mann Whitney U test. Non-correlated categorical data, including the primary outcome, and need for RRT, renal recovery and hospital mortality, will be reported as proportions and compared using Fisher's Exact Test. If necessary, multi-variable logistic or linear regression will be used to control for potential confounding from imbalances in baseline characteristics after randomization.

The tertiary analysis will evaluate for differences between furosemide and placebo in the change of novel serum and urine biomarkers for AKI, defined by absolute levels and relative to baseline (enrollment) at 12 hours, 24 hours and at the time of initiation of RRT, renal recovery or ICU discharge. All samples will remain blinded during processing, storage and analysis. Normally distributed correlated data will be analyzed by the repeated measures ANOVA. Non-normally distributed correlated data will be analyzed by the Friedman test. Correlated categorical data will analyzed by generalized estimating equations. The diagnostic and predictive characteristics of absolute values and relative changes in novel serum and urine biomarkers for progression of AKI as well as need for RRT will be evaluated by $2 \times 2$ 
tables and construction of receiver operator characteristic curves. A p-value of $<0.05$ will be considered significant. All statistical tests will be two-sided.

\section{Data Safety and Monitoring}

The trial will have a data safety and monitoring committee (DSMC) that will consist of four members. Three members will constitute a quorum. The membership consists of persons independent of the Principal Investigator who have no financial, scientific, or other conflict of interest with the trial. Current or past collaborators of Principal Investigator are not eligible to serve on the DSMC. Members of the DSMC will have clinical/content expertise in acute kidney injury; clinical trial methodology and/or biostatistics. The DSMC will meet twice per year during the trial.

\section{Ethical Considerations}

The study has been reviewed and approved by the Health Research Ethics Board at the University of Alberta (File \# 7362) (Additional File 1).

\section{Potential Challenges with the Trial}

Research in patients with AKI has been traditionally challenging due to lack of a standardized definition or classification scheme for AKI. In order to address this issue, and optimize the potential generalizability, we have incorporated the RIFLE definition/classification system for AKI[42]. This consensus definition has now been validated and its clinical use is strengthened by its objectivity, simplicity and by the incorporation of a system to categorize the changes in severity of AKI over time.

The development of acute pulmonary edema in an ICU patient with AKI was identified in our survey as an indication for urgent furosemide or RRT and as such a potential barrier to compliance with our trial[20]. We have addressed this in our protocol by including a provision for the urgent use of furosemide in any enrolled patient with pulmonary edema at the discretion of the consultant ICU physician. Similarly, RRT can be initiated at any time.

Another potential issue with the protocol was the handling of an excess diuresis following initiation of the study drug. To address this, we have incorporated into our study algorithm provisions to temporarily discontinue the study drug in the event of an excess diuresis. Similarly, electrolyte abnormalities, in particular low magnesium and potassium, are common with use of furosemide. This issue is addressed by our ICU having standardized protocols for the replacement of both of these electrolytes in the event they are significantly low.

We do not anticipate any losses to follow-up during the study intervention. This is due to our primary outcome, progression in severity of kidney injury in AKI, being measured while the patient is admitted to ICU. A situation may arise where a patient is randomized and allocated as non-septic but subsequently develops sepsis during the trial. We will address this potential issue by analyzing all these patients according to their initial allocated group.

\section{Discussion}

Furosemide continues to be commonly used in critically ill patients with AKI despite conflicting data on its efficacy and safety from clinical studies. This observation implies there is a misalignment between available evidence and clinical practice. Moreover, this suggests there is clinical equipoise for and there is an urgent need to generate higher-quality evidence on the safety and efficacy of furosemide from randomized trials to guide on this issue. This protocol, for a phase II randomized, blinded, placebo-controlled trial of a low-dose continuous infusion of furosemide, titrated to the physiology parameter of urine output, in critically ill patients early onset AKI, proposes to inform on this issue and potentially aid in the development, design and conduct of a phase III trial powered to evaluate a clinically relevant outcome such as renal replacement therapy or mortality.

Additional file 1: Ethics Approval forms - SPARK Study HREB and $\mathrm{CH}$ ethics approval forms.

Additional file 2: Summary of SPARK Study profile on the Albert Innovates - Health Solutions (formerly the Alberta Heritage Foundation for Medical Research) website.

Additional file 3: Summary of SPARK Study funding from Albert Innovates - Health Solutions (formerly the Alberta Heritage Foundation for Medical Research).

\section{Acknowledgements}

This study is funded by a grant from the Albert Innovates - Health Solutions (formerly the Alberta Heritage Foundation for Medical Research) (Additional Files 2 and 3). Dr. Bagshaw is supported by a Clinical Investigator Award from the Alberta Heritage Foundation for Medical Research.

\section{Author details}

'Division of Critical Care Medicine, Faculty of Medicine and Dentistry, University of Alberta, 3C1.12 Walter C. Mackenzie Centre, 8440-112 Street, Edmonton, Alberta T6G 2B7, Canada. ${ }^{2}$ Division of General Internal Medicine, Faculty of Medicine and Dentistry, University of Alberta, 2E3.24 Walter C. Mackenzie Centre, 8440-112 Street, Edmonton, Alberta T6G 2B7, Canada. ${ }^{3}$ Department of Intensive Care, Austin Hospital, Studley Rd, Heidelberg, Victoria, 3084, Australia.

\section{Authors' contributions}

SMB, FAM, RB designed the trial; SMB, RTNG, FAM, RB obtained funding for the trial; SMB drafted the manuscript; SMB, RTNG, FAM, RB provided critical revision of the manuscript. All authors read and approved the final manuscript.

\section{Competing interests}

The authors declare that they have no competing interests. 
Received: 12 February 2010 Accepted: 11 May 2010

Published: 11 May 2010

\section{References}

1. Ali T, Khan I, Simpson W, Prescott G, Townend J, Smith W, Macleod A: Incidence and outcomes in acute kidney injury: a comprehensive population-based study. J Am Soc Nephrol 2007, 18:1292-1298.

2. Bagshaw SM, George C, Bellomo R: Changes in the incidence and outcome for early acute kidney injury in a cohort of Australian intensive care units. Crit Care 2007, 11:R68

3. Xue JL, Daniels F, Star RA, Kimmel PL, Eggers PW, Molitoris BA, Himmelfarb J, Collins AJ: Incidence and mortality of acute renal failure in Medicare beneficiaries, 1992 to 2001. J Am Soc Nephrol 2006, 17:1135-1142.

4. Uchino S, Kellum JA, Bellomo R, Doig GS, Morimatsu H, Morgera S, Schetz M, Tan I, Bouman C, Macedo E, Gibney N, Tolwani A, Ronco C, Beginning and Ending Supportive Therapy for the Kidney (BEST Kidney) Investigators: Acute renal failure in critically ill patients: a multinational, multicenter study. JAMA 2005, 294:813-818.

5. Bagshaw SM, Laupland KB, Doig CJ, Mortis G, Fick GH, Mucenski M, Godinez-Luna T, Svenson LW, Rosenal T: Prognosis for long-term survival and renal recovery in critically ill patients with severe acute renal failure: a population-based study. Crit Care 2005, 9:R700-R709.

6. Korkeila M, Ruokonen E, Takala J: Costs of care, long-term prognosis and quality of life in patients requiring renal replacement therapy during intensive care. Intensive Care Med 2000, 26:1824-1831.

7. Liano F, Junco E, Pascual J, Madero R, Verde E: The spectrum of acute renal failure in the intensive care unit compared with that seen in other settings. The Madrid Acute Renal Failure Study Group. Kidney Int Supp/ 1998, 66:S16-24

8. Manns B, Doig CJ, Lee H, Dean S, Tonelli M, Johnson D, Donaldson C: Cost of acute renal failure requiring dialysis in the intensive care unit: clinical and resource implications of renal recovery. Crit Care Med 2003, 31:449-455.

9. Metnitz PG, Krenn CG, Steltzer H, Lang T, Ploder J, Lenz K, Le Gall JR, Druml W: Effect of acute renal failure requiring renal replacement therapy on outcome in critically ill patients. Crit Care Med 2002, 30:2051-2058.

10. Wald R, Quinn RR, Luo J, Li P, Scales DC, Mamdani MM, Ray JG: Chronic dialysis and death among survivors of acute kidney injury requiring dialysis. Jama 2009, 302:1179-1185.

11. Hamel MB, Phillips RS, Davis RB, Desbiens N, Connors AF Jr, Teno JM, Wenger N, Lynn J, Wu AW, Fulkerson W, Tsevat J: Outcomes and costeffectiveness of initiating dialysis and continuing aggressive care in seriously ill hospitalized adults. SUPPORT Investigators. Study to Understand Prognoses and Preferences for Outcomes and Risks of Treatments. Ann Intern Med 1997, 127:195-202.

12. Kellum JA, Leblanc M, Gibney RTN, Tumlin J, Lieberthal W, Ronco C. Primary prevention of acute renal failure in the critically ill. Current Opinion in Critical Care 2005, 11(6):537-541.

13. Abel RM, Beck CH Jr, Abbott WM, Ryan JA, Barnett GO Jr, Fischer JE: Improved survival from acute renal failure after treatment with intravenous essential L-amino acids and glucose. Results of a prospective, double-blind study. N Engl J Med 1973, 288:695-699.

14. De Torrente A, Miller PD, Cronin RE, Paulsin PE, Erickson AL, Schrier RW: Effects of furosemide and acetylcholine in norepinephrine-induced acute renal failure. Am J Physiol 1978, 235:F131-136.

15. Kramer HJ, Schuurmann J, Wassermann C, Dusing R: Prostaglandinindependent protection by furosemide from oliguric ischemic renal failure in conscious rats. Kidney Int 1980, 17:455-464.

16. Aravindan N, Aravindan S, Riedel BJ, Weng HR, Shaw AD: Furosemide prevents apoptosis and associated gene expression in a rat model of surgical ischemic acute renal failure. Ren Fail 2007, 29:399-407.

17. Aravindan N, Shaw A: Effect of furosemide infusion on renal hemodynamics and angiogenesis gene expression in acute renal ischemia/reperfusion. Ren Fail 2006, 28:25-35.

18. Bouchard J, Soroko SB, Chertow GM, Himmelfarb J, Ikizler TA, Paganini EP, Mehta RL: Fluid accumulation, survival and recovery of kidney function in critically ill patients with acute kidney injury. Kidney Int 2009, 76:422-427.
19. Payen D, de Pont AC, Sakr Y, Spies C, Reinhart K, Vincent JL: A positive fluid balance is associated with a worse outcome in patients with acute renal failure. Crit Care 2008, 12:R74

20. Bagshaw SM, Delaney A, Jones D, Ronco C, Bellomo R: Diuretics in the management of acute kidney injury: A multinational survey. Contrib Nephrol 2007, 156:236-249

21. Uchino S, Doig GS, Bellomo R, Morimatsu H, Morgera S, Schetz M, Tan I, Bouman C, Nacedo E, Gibney N, Tolwani A, Ronco C, Kellum JA, Beginning and Ending Supportive Therapy for the Kidney (B.E.S.T. Kidney) Investigators: Diuretics and mortality in acute renal failure. Crit Care Med 2004, 32:1669-1677.

22. Cantarovich F, Fernandez JC, Locatelli A, Perez Loredo J: Frusemide in high doses in the treatment of acute renal failure. Postgraduate Medical Journal 1971, 47(Suppl):13-17.

23. Cantarovich F, Galli C, Benedetti L, Chena C, Castro L, Correa C, Perez Loredo J, Fernandez JC, Locatelli A, Tizado J: High dose frusemide in established acute renal failure. British Medical Journal 1973, 4:449-450.

24. Cantarovich F, Rangoonwala B, Lorenz H, Verho M, Esnault VL: High-dose furosemide for established ARF: a prospective, randomized, doubleblind, placebo-controlled, multicenter trial. Am J Kidney Dis 2004, 44:402-409.

25. Chandra M, Agarwal SS, Mitra NK, Gupta NN: Massive intravenous frusemide therapy in acute renal failure. J Indian Med Assoc 1975, 64:47-48.

26. Lucas CE, Zito JG, Carter KM, Cortez A, Stebner FC: Questionable value of furosemide in preventing renal failure. Surgery 1977, 82:341-320.

27. Seedat YK: High dose frusemide in established acute renal failure. $\mathrm{Br} \mathrm{Med}$ J 1973, 4:784.

28. Sirivella S, Gielchinsky I, Parsonnet V: Mannitol, furosemide, and dopamine infusion in postoperative renal failure complicating cardiac surgery. Annals of Thoracic Surgery 2000, 69:501-506.

29. Weinstein JM, Heyman S, Brezis M: Potential deleterious effect of furosemide in radiocontrast nephropathy. Nephron 1992, 62:413-415.

30. Zito J, Cortez A, Lucas CE, Stebner FC, Rosenberg IK, Jaanimagi JL: Distribution of renal blood flow after furosemide in critically ill patients. Surg Forum 1976, 27:27-29.

31. Mehta RL, Pascual MT, Soroko S, Chertow GM, Group PS: Diuretics, mortality, and nonrecovery of renal function in acute renal failure[see comment]. JAMA 2002, 288:2547-2553.

32. Karayannopoulos S: High-dose frusemide in renal failure. Br Med J 1974, 2:278-279

33. Kleinknecht D, Ganeval D, Gonzalez-Duque LA, J F: Furosemide in acute oliguric renal failure. A controlled trial. Nephron 1976, 17:51-58.

34. Shilliday IR, Quinn KJ, Allison ME: Loop diuretics in the management of acute renal failure: a prospective, double-blind, placebo-controlled, randomized study. Nephrology Dialysis Transplantation 1997, 12:2592-2596.

35. Vargas Hein O, Staegemann M, Wagner D, von Heymann C, Martin M, Morgera S, Spies C: Torsemide versus furosemide after continuous renal replacement therapy due to acute renal failure in cardiac surgery patients. Renal Failure 2005, 27:385-392.

36. Kellum JA: Diuretics in acute renal failure: protective or deleterious. Blood Purif 1997, 15:319-322.

37. Lameire $\mathrm{N}$, Vanholder $\mathrm{R}$, Van Biesen W: Loop diuretics for patients with acute renal failure: helpful or harmful? Jama 2002, 288.2599-2601.

38. Noble DW: Acute renal failure and diuretics: propensity, equipoise, and the need for a clinical trial. Critical Care Medicine 2004, 32:1794-1795.

39. Schetz M: Should we use diuretics in acute renal failure? Best Pract Res Clin Anaesthesiol 2004, 18:75-89.

40. Ho KM, Sheridan DJ: Meta-analysis of frusemide to prevent or treat acute renal failure. Bmj 2006

41. Bagshaw SM, Delaney A, Haase M, Ghali WA, Bellomo R: Loop diuretics in the management of acute renal failure: a systematic review and metaanalysis. Crit Care Resusc 2007, 9:68

42. Bellomo R, Ronco C, Kellum JA, Mehta RL, Palevsky P: Acute renal failure definition, outcome measures, animal models, fluid therapy and information technology needs: the Second International Consensus Conference of the Acute Dialysis Quality Initiative (ADQI) Group. Crit Care 2004, 8:R204-212.

43. Bone RC, Balk RA, Cerra FB, Dellinger RP, Fein AM, Knaus WA, Schein RM, Sibbald WJ: Definitions for sepsis and organ failure and guidelines for 
the use of innovative therapies in sepsis. The ACCP/SCCM Consensus Conference Committee. American College of Chest Physicians/Society of Critical Care Medicine. Chest 1992, 101:1644-1655.

44. Ostermann M, Alvarez G, Sharpe MD, Martin CM: Frusemide administration in critically ill patients by continuous compared to bolus therapy. Nephron Clin Pract 2007, 107:c70-76.

45. Devine BJ: Gentamicin therapy. Drug Intell Clin Pharm 1974, 8:650-655.

46. Hoste EA, Clermont G, Kersten A, Venkataraman R, Angus DC, De Bacquer D, Kellum JA: RIFLE criteria for acute kidney injury are associated with hospital mortality in critically ill patients: a cohort analysis. Crit Care 2006, 10:R73.

47. Bagshaw SM, Uchino S, Bellomo R, Morimatsu H, Morgera S, Schetz M, Tan I, Bouman C, Macedo E, Gibney N, Tolwani A, Oudemans-van Straaten HM, Ronco C, Kellum JA, Beginning and Ending Supportive Therapy for the Kidney (BEST Kidney) Investigators: Septic acute kidney injury in critically ill patients: Clinical characteristics and outcomes. Clin J Am Soc Nephrol 2007, 2:431-439.

doi:10.1186/1745-6215-11-50

Cite this article as: Bagshaw et al.: The SPARK Study: a phase II randomized blinded controlled trial of the effect of furosemide in critically ill patients with early acute kidney injury. Trials 2010 11:50.

\section{Submit your next manuscript to BioMed Central} and take full advantage of:

- Convenient online submission

- Thorough peer review

- No space constraints or color figure charges

- Immediate publication on acceptance

- Inclusion in PubMed, CAS, Scopus and Google Scholar

- Research which is freely available for redistribution

Submit your manuscript at www.biomedcentral.com/submit 